\title{
Gemcitabine and Cisplatin Versus Methotrexate, Vinblastine, Doxorubicin, and Cisplatin In Advanced and or Metastatic Bilharzial Urothelial Carcinoma of the Bladder in Egypt.
}

\author{
Mervat Mohamed Omar, Samy M Al-Gezawy and Hanan Gamal-Eldin Mostafa
}

\author{
Department of Clinical Oncology, Faculty of Medicine, Assiut University.
}

\begin{abstract}
Purpose: Gemcitabine plus cisplatin (GC) and methotrexate, vinblastine, doxorubicin, and cisplatin (MVAC) were compared in patients with locally advanced or metastatic bilharzial urothelial carcinoma.

Patients and Methods: Patients with with locally advanced or metastatic bilharzial urothelial carcinoma (no prior systemic chemotherapy) were randomized to GC (gemcitabine $1,000 \mathrm{mg} / \mathrm{m}^{2}$ days $1,8,15$, cisplatin $70 \mathrm{mg} / \mathrm{m}^{2}$ day 2) or standard MVAC every 28 days for a maximum of six cycles (Methotrexate $=30 \mathrm{mg} / \mathrm{m}^{2}$ on days 1,15 and 22 , Vinblastine $=3 \mathrm{mg} / \mathrm{m}^{2}$ on days 2,15 and 22,Doxorubicin $=30 \mathrm{mg} / \mathrm{m}^{2}$ on day 2 and Cisplatin $=70 \mathrm{mg} / \mathrm{m}^{2}$ on day 2 (1-2 $\mathrm{h}$ infusion).

Results: forty-one patients were randomized, twenty-one to the GC arm and twenty to the MVAC arm. Overall survival was similar(13 months) on both arms. Time to progressive disease was 7 months with GC group and 6 months with MVAC group and response rate (GC, 47.6\% vs MVAC 45\%). Significant prognostic factors correlating with better overall survival were Karnofsky performance status $\geq 70$, TNM staging (Mo vs.M1) and the absence of visceral metastasis. Hematologic toxicities were significantly higher with GC therapy. More GC patients, compared with MVAC patients had grade $3 / 4$ anemia (28.5\% vs $15 \%$ ) and thrombocytopenia (47.6\% vs 25\%). More MVAC patients, compared with GC patients had grade $3 / 4$ neutropenia (80\% vs $67.6 \%$ $P=0.001)$, grade $3 / 4$ mucositis $(20 \% \mathrm{v} 9.5 \%)$ and alopecia $(25 \% \mathrm{v} 14.3 \%)$

Conclusion: GC provides a similar survival advantage to MVAC with a better tolerability. These results strengthen the role of GC as a standard of care in patients with locally advanced or metastatic bilharzial-related urothelial carcinoma.
\end{abstract}

Key words: Gl, M-Vac, Bladden Carcinoma

Corresponding Author: Mervat Mohamed Omar

E-mail: drmervatomar@yahoo.com

\section{INTRODUCTION}

Carcinoma of the bladder is the most prevalent cancer in Egypt. At the National Cancer Institute (NCI), Cairo University, it constitutes $10.1 \%$ of all cancers for both sexes together ${ }^{1}$. In addition to the unique biological, epidemiological, pathological and clinical characteristics of bilharzial bladder cancer compared with the conventional transitional cell carcinoma seen in Western countries ${ }^{2}$, the disease also has a different chemoresponsiveness profile, as reported in a series of phase II single-agent and combination chemotherapy trials $^{3,4}$.

The standard chemotherapy regimen for advanced bladder cancer for more than a decade was methotrexate, vinblastine, doxorubicin, and cisplatin (MVAC) $)^{5,6}$. Compared with cisplatin alone, M-VAC is the only treatment that has a better overall response rate $(39 \%$ vs. $12 \%$ ), progression-free time (10 vs. 4.3 months), and survival (12.5 vs. 8.2 months $)^{7}$. The significant toxicity associated with M-VAC regimen, including thrombocytopenia, neutropenia with neutropenic fever and significant mucositis, in addition to nausea and vomiting, renal, cardiac, and neurologic toxicities, limits its use as a palliative treatment ${ }^{5}$. In an attempt to identify treatment regimen with better toxicity profile, many new cytotoxic agents have been introduced. Gemcitabine (Gemzar), a pyrimidine antimetabolite, has been studied as a single agent for treatment of metastatic bladder cancer with promising results ${ }^{8}$ then, combination of Gemcitabine with cisplatin (GC) against transitional cell bladder cancer with promising results ${ }^{9-11}$. Based on these encouraging results, GC is generally considered the current standard of care for metastatic urothelial bladder cancer. However, it has not been sufficiently tested yet against MVAC in advanced bilharzial-related bladder cancer $^{12}$.

The aim of this study was to compare the efficacy and toxicity of GC with MVAC in advanced bilharzialrelated urothelial carcinoma of the bladder. 


\section{PATIENTS AND METHODS}

Between May 2002 till January 2005, 41 patients with advanced bilharzial urothelial carcinoma of the bladder presenting at Assiut University Oncology Department were enrolled in this prospective randomized trial.

\section{Eligibility Criteria:}

Patients included on this study had these criteria:

1. Histologically proven locally advanced (T4, N2, N3), inoperable recurrent or metastatic (M1) transitional cell carcinoma of the bladder.

2. Histologically documented bilharziasis by the presence of bilharzia ova in bladder tumour tissue obtained during primary diagnosis.

3. Measurable or evaluable disease.

4. Age $\geq 18$ years.

5. Performance status $\geq 70 \%$ Karnofsky scale.

6. Adequate haematological, liver and renal functions with estimated creatinine clearance of at least $60 \mathrm{ml} / \mathrm{min}$.

7. No prior systemic chemotherapy or radiotherapy.

\section{Exclusion criteria:}

1. Patients with other histologicsl subtyptes.

2. Performance states $<70 \%$ karnofsky scale.

3. Patients with prior chemotherapy or radiotherapy.

4. Patients with inadequate bone marrow reserve.

5. Inadequate renal and liver functions.

All patients had chest X-ray, abdomino-pelvic CT scan, bone scan and echocardiography to assess left ventricular ejection fraction (LVEF) in arm II patients.

\section{Treatment protocol:}

\section{Patients were randomized to receive:}

- Arm A = systemic chemotherapy GC:

Gemcitabine $=1.000 \mathrm{mg} / \mathrm{m}^{2}$ over 30 to 60 minutes i.v. days 1,8 and 15 plus.

Cisplatin $=70 \mathrm{mg} / \mathrm{m}^{2}$ on days $2(1-2 \mathrm{~h}$ infusion $)$.

- Arm B = systemic chemotherapy MVAC:

Methotrexate $=30 \mathrm{mg} / \mathrm{m}^{2}$ on days 1,15 and 22 .

Vinblastine $=3 \mathrm{mg} / \mathrm{m}^{2}$ on days 2,15 and 22 .

Doxorubicin $=30 \mathrm{mg} / \mathrm{m}^{2}$ on day 2 .

Cisplatin $=70 \mathrm{mg} / \mathrm{m}^{2}$ on day $2(1-2 \mathrm{~h}$ infusion $)$.

- Cisplatin was administered with adequate pre-and post-hydration.

- During treatment, blood counts and serum chemistries were performed weekly.

- Patients received treatment every 4 weeks for a maximum of six cycles unless they developed progression of disease or unacceptable toxicity.

- On both arms dose was adjusted for hematologic and/or non- hematologic toxicity. If the WBC was lower than $3.0 \times 10^{9} / \mathrm{L}$ or the platelets below $100 \times 10^{9} / \mathrm{L}$ on day 29 , the subsequent cycle was delayed for one week. For days 8, 15 and 22, the doses were omitted if these counts were less than 2.0 or $50 \times 10^{9} / \mathrm{L}$, respectively. For other non-haematological toxicities, the drugs were given at $50 \%$ of planned doses or omitted if Common Toxicity Criteria grade 3 or 4 toxicities occurred.

- All patients provided a written informed consent.

\section{Treatment Evaluation}

Tumor assessments were done every two cycles radiologically and by physical examinations. Responses were classified according to (World Health Organization) criteria. Complete response (CR) was defined as the disappearance of all known disease for at least 4 weeks. Partial response (PR) was achieved if total tumor size decreased by at least $50 \%$ of the measurable lesions without appearance of any new lesions for at least 4 weeks. Stable disease (SD) was reached if reduction of less than $50 \%$ or an increase of less than $25 \%$ of all measurable disease with no appearance of new lesions for at least 4 weeks. Progressive disease occurred if the size of at least one measurable lesion increased by at least $25 \%$ or new lesions appeared ${ }^{13}$. All toxicities were graded using the WHO scale ${ }^{14}$.

Overall survival was measured from date of diagnosis until death and time to progressive disease was measured from date of initial treatment until disease progression.

\section{Statistical analysis:}

Overall survival and time to progression were estimated by Kaplan Meier methods ${ }^{8}$.

The comparison between survivals of the two groups was performed using the log rank test. A $P$-value of $\leq 0.05$ was considered significant.

\section{RESULTS}

Between May 2002 and January 2005, forty-one patients enrolled the study. Twenty-one patients were randomized to gemcitabine-cisplatin and twenty to MVAC arm. Patients characteristics were generally well balanced between treatment arms as shown in (Table 1). The median length of follow up was 22 months.

\section{Overall survival:}

Overall survival was similar on both arms. Median survival was 13 months with GC and MVAC, survival rates at 6 months, 12 months, and 18 months was $85 \%$, $42 \%$ and $35 \%$, respectively on GC and $82 \%, 44 \%, 37 \%$, respectively on MVAC. Figure 1 provides survival 
curves for each treatment arm. Univariate analyses showed that prognostic factors correlating with poorer overall survival were Karnofsky performance status $<70 \%$, TNM staging (M1) and the presence of visceral metastases, (Table 2). When treatment was added to this final model of prognostic factors there was no treatment effect for overall survival.

\section{Tumor response:}

Overall response rates were not significant between both arms, most responses were partial. Overall response rate was $47.6 \%$ with $\mathrm{GC}(14.3 \% \mathrm{CR}$ and $33.3 \% \mathrm{PR})$ and $45 \%$ with MVAC (10\% CR and $35 \%$ $\mathrm{PR}),(P=0.48)$. Disease stabilization was reached in $28.6 \%$ and $30 \%$ of patients and disease progressed in $23.8 \%$ and $25 \%$ of patients in GC and MVAC, respectively.

\section{Time to progressive disease:}

Time to progressive disease was comparable on both arms. Median time to progressive disease was 7 months with CG (6.4 to 8.4 months) and 6 months with MVAC (5.3 to 7.4 months). Figure 2 provides time to progressive curves for each treatment arms. At the time of analysis 10 patients had progressed (CG, $\mathrm{n}=5$ MVAC, $\mathrm{n}=5)$. Summary of efficacy outcomes are provided in (Table 4).

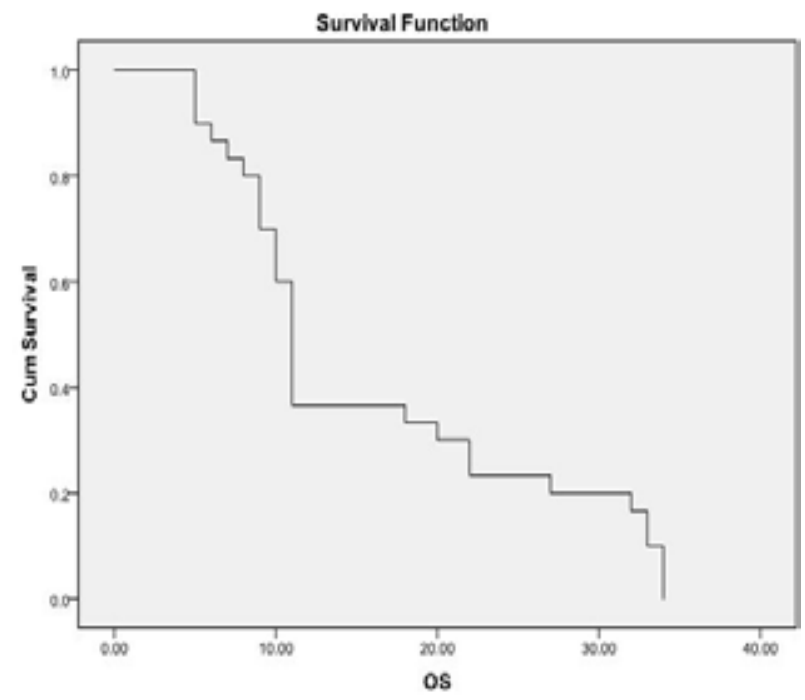

Figure 1: Overall survival

\section{Toxicity:}

On GC arm, 12 patients (57\%) were given cycles without any dose adjustments or treatment delays compared with 6 patients $(30 \%)$ on the MVAC arm. The most common cause for adjustments on GC arm was thrombocytopenia, while on the MVAC arm, the most common causes for adjustments were leucopenia, and mucositis.

The toxicities seen in both treatment arms were expected. World health organisation grades 3 and 4 toxicities for hematological and non hematological toxicties are shown in (Table 5). Grade 3 and 4 anaemia was seen more often on the $\mathrm{GC}$ arm than on MVAC $\operatorname{arm}(\mathrm{GC}=28.56 \%$, MVAC $=$ $15 \% . P=0.02$ ). Grade 3 and 4 thrombocytopenia was seen more often on GC on (GC: $47.64 \%$, MVAC: $25 \% P=0.03$ ) but with no grade 4 bleeding on either arm.

Grade 3 and 4 Neutropenia was significantly more common in MVAC arm (MVAC: $80 \%, \mathrm{GC}=67.6 \%$ $P=.001)$. More patients on MVAC developed febrile neutropenia $(20 \%$ vs. $4.8 \% P=0.04)$.

For non hematologic toxicities, patients on MVAC experienced more grades $3 \& 4$ mucositis (MVAC $=20 \%$ GC" $9.5 \% P=0.03$ ). Gastrointestinal toxicities like nausea, vomiting, diarrhea, and constipation are more or less the same between both arms., alopecia was more in MVAC patients $(25 \%$ Vs $14.3 \% P=0.02)$.

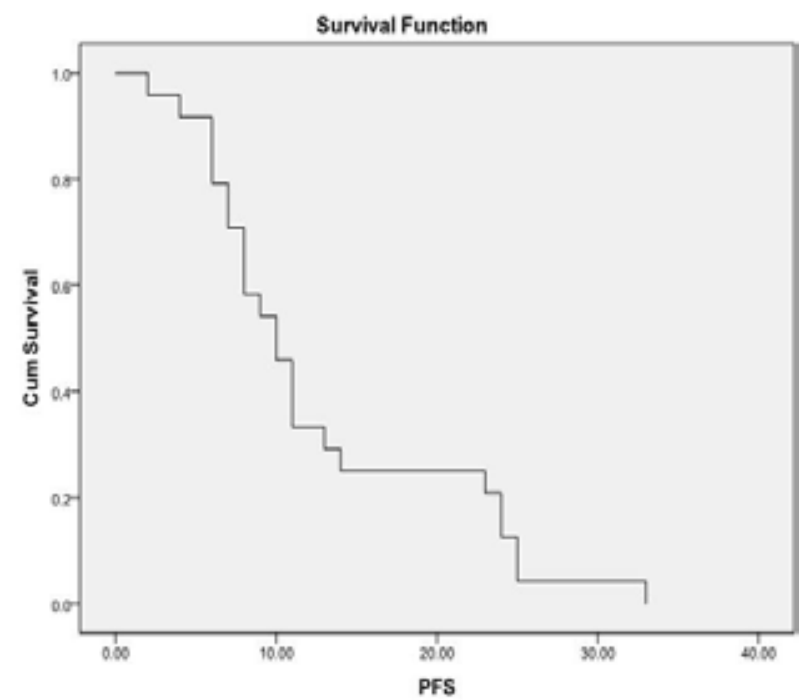

Figure 2: Time to progressive disease. 
Kasr-El-Aini Journal Of Clinical Oncology And Nuclear Medicine

Vol. 7 | No. 3-4 2011

Gemcitabine and Cisplatin Versus Methotrexate, Vinblastine

Table 1: Patient characteristics (41 patients).

\begin{tabular}{|c|c|c|}
\hline Parameter & $\operatorname{Arm} A=21$ patients GC No $(\%)$ & Arm $B=20$ patients MVAC No $(\%)$ \\
\hline Age, median, years & 63 & 63 \\
\hline Male & $18(86)$ & $15(75)$ \\
\hline Performance status $\geq 70 \%$ & $11(52)$ & $8(40)$ \\
\hline \multicolumn{3}{|l|}{ Pathological grade } \\
\hline 1 & $3(14)$ & $4(20)$ \\
\hline 2 & $8(38)$ & $7(35)$ \\
\hline 3 & $10(48)$ & $9(45)$ \\
\hline Locally advanced & $12(57)$ & $10(50)$ \\
\hline Metastatic disease & $9(43)$ & $10(50)$ \\
\hline Bone & $5(23)$ & $5(25)$ \\
\hline Liver & $2(10)$ & $2(10)$ \\
\hline Lung & $2(10)$ & $3(15)$ \\
\hline
\end{tabular}

Abbreviation: $\mathrm{GC}=$ gemcitabine, cisplatin, $\mathrm{MVAC}=$ methotrexate, vinblastine, doxorubicin, cisplatin, $\mathrm{PS}=$ performance status .

Table 2: Univariate analysis of prognostic factors.

\begin{tabular}{|c|c|c|c|}
\hline Prognostic factor & GC "n = 21" & MVAC "n = 20" & OSHR $(95 \% \mathrm{CI})$ \\
\hline $\begin{aligned} 1-\mathrm{PS} & =\text { Good }>70 \\
& =\text { Poor }<70\end{aligned}$ & $\begin{array}{l}11(52.4 \%) \\
10(47.6 \%)\end{array}$ & $\begin{array}{c}8(40 \%) \\
12(60 \%)\end{array}$ & $\begin{array}{c}1.92(1.23-2.71) \\
P=0.01^{*}\end{array}$ \\
\hline $\begin{array}{r}2-\mathrm{TNM}=\mathrm{M} 1 \\
\mathrm{M} 0\end{array}$ & $\begin{array}{l}12(27.1 \%) \\
9(42.9 \%)\end{array}$ & $\begin{array}{c}7(35 \%) \\
13(65 \%)\end{array}$ & $\begin{array}{c}1.78(1.03-2.04) \\
P=0.02 *\end{array}$ \\
\hline $\begin{aligned} 3-\text { nodal.status }= & - \text { ve } \\
& + \text { ve }\end{aligned}$ & $\begin{array}{c}9(42.9 \%) \\
12(57.1 \%)\end{array}$ & $\begin{array}{l}10(20 \%) \\
10(20 \%)\end{array}$ & $\begin{array}{c}1.13(0.85-1.41) \\
P=0.442 \mathrm{n} . \mathrm{s}\end{array}$ \\
\hline $\begin{array}{c}\text { 4-Visceral metastasis. } \\
\text { - ve } \\
+ \text { ve }\end{array}$ & $\begin{array}{c}16(76.2 \%) \\
5(23.8 \%)\end{array}$ & $\begin{array}{c}16(80 \%) \\
4(20 \%)\end{array}$ & $\begin{array}{c}2.01(1.72-2.85) \\
P=0.01^{*}\end{array}$ \\
\hline $\begin{array}{r}\text { 5- Responce: }(\mathrm{CR}+\mathrm{PR}) \\
(\mathrm{SD}+\mathrm{PD})\end{array}$ & $\begin{array}{l}10(47.6 \%) \\
11(52.4 \%)\end{array}$ & $\begin{array}{c}9(45 \%) \\
11(55 \%)\end{array}$ & $\begin{array}{c}1.25(0.93-201) \\
P=0.981 \mathrm{n} . \mathrm{s}\end{array}$ \\
\hline $\begin{aligned} 6-\mathrm{Sex}= & \text { male } \\
& \text { Fcmale }\end{aligned}$ & $\begin{array}{c}18(85.7 \%) \\
3(14.3 \%)\end{array}$ & $\begin{array}{c}15(75 \%) \\
5(25 \%)\end{array}$ & $\begin{array}{c}1.92(1.58-2.43) \\
P=0.319 \text { n.s }\end{array}$ \\
\hline
\end{tabular}

Table 3: Results of response to gemcitabime plus cisplation (A) and methotrexate, vimblastion, adriamycin and cisplation in advanced urothelial cancer.

\begin{tabular}{lcc}
\hline Response & $\begin{array}{c}\text { Arm A (21 patients) } \\
\text { GC No (\%) }\end{array}$ & $\begin{array}{c}\text { A rm B= 20 Patients } \\
\text { MVAC No (\%) }\end{array}$ \\
\hline Complete response (CR) & $3(14.3)$ & $2(10)$ \\
\hline Partial response (RR) & $7(33.3)$ & $7(35)$ \\
\hline Stable disease (SD) & $6(28.6)$ & $6(30)$ \\
\hline Progressive disease (PD) & $5(23.8)$ & $5(35)$ \\
\hline
\end{tabular}

Table 4: Summary of efficacy outcomes.

\begin{tabular}{lccc}
\hline Parameter & GC months & MVAC months & P value \\
\hline Median overall survival & 13 & 13 & - \\
\hline Median TTPD & 7 & 6 & $0.521 \mathrm{~ns}$ \\
\hline Response rate \% & 47.6 & 45 & $0.483 \mathrm{~ns}$ \\
\hline Abbreviation: TTPD, time to progressive disease, & & &
\end{tabular}


Table 5: Maximum toxicity grade.

\begin{tabular}{|c|c|c|c|c|c|}
\hline \multirow{3}{*}{ Toxicity } & \multicolumn{2}{|c|}{ GC \% of patients } & \multicolumn{2}{|c|}{ MVAC \% of patients } & \multirow{3}{*}{$\boldsymbol{P}$} \\
\hline & \multicolumn{2}{|c|}{ Grade } & \multicolumn{2}{|c|}{ Grade } & \\
\hline & 3 & 4 & 3 & 4 & \\
\hline \multicolumn{6}{|l|}{ Hematologic } \\
\hline Anemia & 23.8 & 4.76 & 15 & 0 & 0.02 \\
\hline Thrombocytopenia & 28.6 & 19.04 & 10 & 15 & 0.03 \\
\hline Neutropenia & 42.8 & 23.8 & 15 & 65 & 0.001 \\
\hline \multicolumn{6}{|l|}{ Non hematologic } \\
\hline Mucositis & 9.5 & 0 & 15 & 5 & 0.03 \\
\hline Nausea/vomiting & 23.8 & 0 & 20 & 0 & 0.237 \\
\hline Diarrhea & 9.5 & 0 & 10 & 0 & 0.653 \\
\hline Infection & 4.8 & 0 & 10 & 5 & 0.04 \\
\hline Pulmonary & 4.8 & 0 & 5 & 5 & 0.673 \\
\hline Haematuria & 9.5 & 0 & - & 0 & 0.221 \\
\hline Constipation & 4.8 & 0 & 5 & 0 & 0.591 \\
\hline Hemorrhage & 4.8 & 0 & 0 & 0 & 0.237 \\
\hline Alopecia & 14.3 & 0 & 25 & 0 & 0.02 \\
\hline
\end{tabular}

\section{DISCUSSION}

Combination chemotherapy is the treatment of choice for patients with inoperable locally-advanced or metastatic bladder cancer. M-VAC was a frequently used regimen for this disease ${ }^{6}$. Although a survival advantage with noted with MVAC compared with cisplatin alnoe ${ }^{7}$, MVAC was associated with significant toxicities with a toxic death rate of 3-4\%. Thus, there was a need for other regimens that provide better survival outcome or similar survival with reduced toxicity. Based on encouraging results of phase III studies comparing gemcitabine and cisplatin with MVAC in bladder cancer ${ }^{8}$, this regimen is generally considered the current standard of care for metastatic TCC of the urothelium. However, it has not been sufficiently tested yet against MVAC in advanced bilharzial-related bladder cancer ${ }^{11}$.

This phase III study comparing, GC with MVAC for efficacy and toxicity in advanced bilharzial-related urothelial carcinoma of the bladder. Our results showed that the combination of gemcitabine and cisplatin obtained a median survival similar to MVAC. In both arms, the overall response rates and the median progression-free survival demonstrated nearly identical results and this indicated nearly similar efficacy of both treatment regimens but $\mathrm{GC}$ is more tolerable and safer, so GC has a better risk-benefit ratio than MVAC.
These results were comparable with the results from studies using the same gemcitabine-cisplatin combination against advanced transitional cell carcinoma ${ }^{8,15,16}$.

However, the overall response rate $(47.6 \%)$ and $\mathrm{CR}$ (14.3) in the GC therapy in this study is lower than the results reported by Khaled HM, et al. ${ }^{17}$. The difference may be due to dose adjustment and frequent omissions of gemcitabine occurred on day 15 in this study.

This study demonstrated that GC is less toxic than MVAC. Patients treated with GC had lower toxicityrelated mortality and lower rates of grade 3 or 4 mucositis. This is in accordance with that reported by Von Der Masse $\mathrm{H}$ et al. ${ }^{8}$ and Khaled HM, et al. ${ }^{17}$.

In this study, overall survival, time to progressive disease and response rates were similar on both arms. The results of our univariate analysis of prognostic factors support the finding of Bajorin et al. who define performance status, stage and presence or absence of visceral metastases as important, independent prognostic variables $^{18}$.

\section{CONCLUSION}

In conclusion, GC therapy is effective for the treatment of advanced or metastatic bilharzial-related 
urothelial carcinoma of the bladder, with an acceptable clinical safety profile. This study also indicates that GC therapy may be better tolerated and safer than MVAC therapy. The promising results of using gemcitabinecisplatin combination in the metastatic setting led to multi-institutional neo-adjuvant trial for organ preservation $^{1}$.

\section{REFERENCES}

1. Khaled HM. Systemic management of bladder cancer in Egypt: Revisited. J.Egypt.Natl.Cancer Inst. 2005;17(3):127-31.

2. Zaghloul MS. Distant metastasis from bilharzial bladder cancer. Cancer 1996;77(4):743-9.

3. Gad El Mawla N, Hamza MR, Zikri ZK, El Serafi M, El Khodary A, Khaled $\mathrm{H}$, et al. Chemotherapy in invasive carcinoma of the bladder. A review of phase II trials in Egypt. Acta Oncol. 1989;28(1):73-6.

4. Khaled HM, Gad El Mawla N, El Said A, Hamza MR, Gaafar R, El Attar I, et al. Combination chemotherapy for advanced bilharzial bladder carcinoma. Ann.Oncol. 1996;7(7):751-4.

5. Sternberg CN, Yagoda A, Scher HI, Watson RC, Geller $\mathrm{N}$, Herr HW, et al. Methotrexate, vinblastine, doxorubicin and cisplatin for advanced transitional cell carcinoma of the urothelium: Efficacy and patterns of response and relapse. Cancer 1989;64(12):2448-58.

6. Sternberg CN, Yagoda A, Scher HI. Preliminary results of M-VAC (methotrexate, vinblastine, doxorubicin and cisplatin) for transitional cell carcinoma of the urothelium. J.Urol. 1985;133(3):403-7.

7. Loehrer Sr. PJ, Einhorn LH, Elson PJ, Crawford ED, Kuebler P, Tannock I, et al. A randomized comparison of cisplatin alone or in combination with methotrexate, vinblastine and doxorubicin in patients with metastatic urothelial carcinoma: A cooperative group study. J.Clin. Oncol. 1992;10(7):1066-73.

8. Von der Maase H. Gemcitabine in transitional cell carcinoma of the urothelium. Expert Rev.Anticancer Ther. 2003;3(1):11-9.

9. Von der Maase H, Hansen SW, Roberts JT, Dogliotti L, Oliver T, Moore MJ, et al. Gemcitabine and cisplatin versus methotrexate, vinblastine, doxorubicin and cisplatin in advanced or metastatic bladder cancer: Results of a large, randomized, multinational, multicenter, phase III study. J.Clin.Oncol. 2000;18(17):3068-77.

10. Kaufman D, Raghavan D, Carducci M, Levine EG, Murphy B, Aisner J, et al. Phase II trial of gemcitabine plus cisplatin in patients with metastatic urothelial cancer. J.Clin.Oncol. 2000;18(9):1921-7.

11. Moore MJ, Winquist EW, Murray N, Tannock IF, Huan $\mathrm{S}$, Bennett $\mathrm{K}$, et al. Gemcitabine plus cisplatin, an active regimen in advanced urothelial cancer: A phase II trial of the National Cancer Institute of Canada Clinical Trials Group. J.Clin.Oncol. 1999;17(9):2876-81.

12. McDougal WS, Shipley WU, Kaufman DS. Cancer of the bladder, ureter and renal pelvis. In: DeVita VT, Lawrence TS, Rosenberg SA, DePinho RA, Weinberg RA, editors. DeVita, Hellman and Rosenberg's cancer: Principles \& practice of oncology. 8th ed.: Lippincott Williams \& Wilkins; 2008. p. 1375.

13. Miller AB, Hoogstraten B, Staquet M, Winkler A. Reporting results of cancer treatment. Cancer 1981;47(1):207-14.

14. World Health Organization (WHO). Handbook for reporting results of cancer treatment.: World Health Organization (WHO); 1980.

15. Von Der Maase H, Andersen L, Crinò L, Weinknecht S, Dogliotti L. Weekly gemcitabine and cisplatin combination therapy in patients with transitional cell carcinoma of the urothelium: A phase II clinical trial. Ann. Oncol. 1999;10(12):1461-5.

16. Roberts JT, von der Maase H, Sengeløv L, Conte PF, Dogliotti L, Oliver T, et al. Long-term survival results of a randomized trial comparing gemcitabine/cisplatin and methotrexate/vinblastine/doxorubicin/cisplatin in patients with locally advanced and metastatic bladder cancer. Ann. Oncol. 2006;17(Suppl. 5):v118-22.

17. Khaled HM, Hamza MR, Mansour O, Gaafar R, Zaghloul MS. A phase II study of gemcitabine plus cisplatin chemotherapy in advanced bilharzial bladder carcinoma. Eur.J.Cancer 2000;36(Suppl. 2):S34-7.

18. Bajorin DF, Dodd PM, Mazumdar M, Fazzari M, McCaffrey JA, Scher HI, et al. Long-term survival in metastatic transitional-cell carcinoma and prognostic factors predicting outcome of therapy. J.Clin.Oncol. 1999;17(10):3173-81. 